Çukurova Üniversitesi Mühendislik Mimarlık Fakültesi Dergisi, 34(1), ss. 211-222, Mart 2019

Çukurova University Journal of the Faculty of Engineering and Architecture, 34(1), pp. 211-222, March 2019

\title{
Yalın Üretim Tekniklerinin Otomotiv Yan Sanayisinde Uygulanmasının Analizi
}

\author{
Serap AKCAN*1, Begüm DEMIRDAK ${ }^{1}$ \\ ${ }^{1}$ Süleyman Demirel Üniversitesi, Mühendislik Fakültesi, Endüstri Mühendisliği Bölümü, Isparta
}

Geliş tarihi: 07.01.2019

Kabul tarihi: 27.03 .2019

$\ddot{\mathbf{O} z}$

Üretim firmalarının sayısındaki artış, işletmelerin rekabetini artırmaktadır. Bu nedenle, minimum israf ve maliyet ile maksimum üretimi gerçekleştirmeyi hedefleyen yalın üretim teknikleri kullanılmaya başlanmıştır. Ancak firmalar, yalın üretimin tam anlamıyla uygulanmasında bazı güçlüklerle karşılaşmaktadırlar. Bu çalışmada, yalın üretime tam uyumluluğun incelenmesi, tüm tekniklerin aktif kullanımının tam anlamıyla analiz edilmesi, adaptasyon sürecinin incelenmesi ve yalın üretimin uygulamalarının benimsenmesinin analiz edilmesi için bir anket çalışması sunulmuştur. Anket sonuçlarına göre bu çalışmada incelenen firmaların yalın üretim uygulamalarını aktif bir şekilde kullandıkları ve yalın üretim tekniklerinin çoğunu birlikte kullanması gerektiği görülmüştür.

Anahtar Kelimeler: Yalın üretim teknikleri, Anket, Korelasyon testi, Mann-Whitney-U testi, Otomotiv yan sanayi

\section{Analyzing the Implementation of Lean Production Techniques in Automotive Supply Industry}

\begin{abstract}
The increase in the number of production firms intensifies the competition of enterprises. For this reason, the lean techniques, which aim the maximum production with minimum waste and cost, came into use. However, firms experience some difficulties while implementing the lean production in its entirety. In this study, a survey is presented for investigation of full compatibility with lean production; in-depth analysis of the active use of all techniques, investigation of the adaptation process and analysis of the adoption of lean manufacturing practices. As a result of the survey, it is seen that firms investigated in this study implement lean production techniques actively and most of the lean production techniques should be used together.
\end{abstract}

Keywords: Lean production techniques, Survey, Correlation test, Mann-Whitney-U test, Automotive supply industry

"Sorumlu yazar (Corresponding author): Serap AKCAN, serapakcan@sdu.edu.tr 


\section{GíRiş}

Gelişen pazar ve üretim yapan firma sayısının artması ile doğru orantılı olarak üretim sektöründe maksimum verim ve minimum maliyeti yakalayarak üretim yapmak en büyük hedef haline gelmiştir. Bu hedefi gerçekleştirmek için farklı üretim sistemleri kullanılmaya başlanmıştır. Bunlardan biri de yalın üretim sistemleridir. $\mathrm{Bu}$ üretim sisteminde her şeyin yalınlaştırılarak maliyetin düşürülmesi amaçlanmıştır. Yalın üretim katma değersiz işleri minimize ederek üretimde hızı hedefler. Fakat yalın üretimi tam anlamıyla uygulamak ve bu düzene geçmek belirli maliyet ve belirli zaman gerektirir. Firmalar bu geçiş sürecinde ve tam anlamiyla bu sistemi oturtmak için bazı zorluklar yaşamaktadırlar. Bu çalışmada yapılan anket çalışması ile yalın üretime tam uyumluluk, tüm yöntemlerin aktif kullanımını tam anlamıyla analiz edip adaptasyon süreci ve devamını inceleyip yalın üretimin uygulamalarının benimsenmesinin incelenmesi hedeflenmiştir.

Literatürde yalın üretim ile ilgili birçok çalışmaya rastlamak mümkündür. Özgiray [1] çalışmasında yalın üretim tekniklerden olan Kaizen, SMED, JIT ve Kanban ile yalın üretimin uygulanabilirliğini sunmuştur. Arslan [2] çalışmasında Türkiye'nin lider bir otobüs üreticisinde yer alan radyatör ön montaj alanını yalın üretim prensiplerine göre analiz etmiştir. Analiz sonucunda, ön montaj zamanlarında ortalama \%42 oranında, alan kullanımında ise $46 \mathrm{~m}^{2}$ alandan kazanç elde edilmiştir. Çobanoğlu [3] çalışmasında yalın üretim uygulamasının bir treyler sektöründe sağladığı kazançları sunmuştur. Küçükuysal [4] çalışmasında otomotiv yan sanayi sektöründe ERP ve yalın üretim analizi sunmuştur. Çalışmanın analizleri sonucunda işletmelerin daha etkin bir üretim yönetimi sağlamak için ERP ve yalın üretimi beraber kullanabileceği vurgulanmıştır. Bulut [5] beyaz eşya yan sanayi sektöründe ERP ve yalın üretimini analiz etmiş ve otomotiv yan sanayi ile karşılaştırmıştır. Gönen [6] otomotiv endüstrisinde yalın üretim ve eşzamanlı mühendislik yaklaşımıyla değer akış haritalandırma yapmıştır. Önerilen gelecek durum ile mevcut durumdaki yarı mamul stoklarında $\% 84$, toplam tip değişim süresinde $\% 31,9$, işlem süresinde $\% 10,2$ ve temin süresinde $\% 74,6$ azalıș sağlanmakta olduğu sonucunu sunmuştur. Özçelik ve Cinoğlu [7] uygulama yapılan işletmede kullanılan ve hata oranı yüksek olan bir konektör için yalın üretim teknikleri (poke-yoke, iş standartlaştırma ve kaizen) ile iyileştirmeler yapmışlardır. $\mathrm{Bu}$ iyileştirmeler sayesinde hata oranı ve hurda maliyetinin önemli ölçüde düşürüldüğü söylenmiştir. Uçan [8] otomotiv yan sanayisinde malzeme besleme sistemini yalın üretim yaklaşımıyla yeniden tasarlamıştır. Belekoukias ve arkadaşları [9] çalışmalarında beş önemli yalın üretim tekniğinin (tam zamanında üretim, otonomasyon, kaizen, toplam üretken bakım ve değer akış haritalama) üretim işletmelerinin operasyonel performansına etkisini incelemişlerdir. Çalışmanın sonucunda, operasyonel performansa, tam zamanında üretim ve otonomasyon yalın tekniklerinin en güçlü etkiyi gösterdiği gözlemlenmiştir. Kılıç [10] çalışmasında yalın üretim tekniklerinin otomotiv yan sanayinde uygulamış ve elde edilen kazanımları sunmuştur. Adalı ve arkadaşları [11] çalışmasında değer akış haritalama tekniğini bir traktör fabrikasında uygulamış ve israf önlenmesi için çevrim süresinde $\% 8$ iyileştirme yaptıklarını sunmuşlardır. Adalı ve Erdem [12] 1sıtma soğutma sistemleri üreten bir işletmede yalın üretim teknikleri kullanarak montaj hattı dengeleme çalışması sunmuşlardır. Marodin ve arkadaşları [13] çalışmalarında Brezilya otomotiv tedarik zincirinde yalın üretim uygulamaları ile operasyonel performans arasındaki ilişkiyi açıklamayı amaçlamışlardır. Çalışmada beş operasyonel performans ölçüsünde 11 yalın uygulamanın etkisi anket analizi yapılarak belirlenmeye çalışılmıştır. Anket Brezilya'da 64 işletmeye uygulanmış ve toplam üretken bakım uygulamasından dolayı tedarik süresinde, tam zamanında üretim adaptasyonu ile de envanterde azalmaların olduğu görülmüştür.

\section{YALIN ÜRETIM SISTEMI}

\subsection{Yalın Üretim}

Üretim endüstrisi, çıktı miktarını artırırken maliyeti azaltabilmek için yalın metodolojisini geliştirmiştir. Yalın metodolojisi Japonya'da 
özellikle Toyota Üretim Sistemi ile ortaya çıkmıştır. Yalın teknikler, atıkları sistematik bir biçimde elemine etmek, hataları önlemek ve her çalışanı süreci iyileştirme ile ilgili değişiklikleri yapmaları konusunda motive etmek için sürekli süreç iyileştirme yöntemlerini içermektedir [14].

\subsection{Yalın Üretim Teknikleri}

\subsubsection{Kaizen}

Mükemmele ulaşma arzusuyla sürekli daha iyisini yapmak için çalışma ve kendini geliştirme felsefesidir. Kaizen daha iyiye ulaşmak için küçük ama sürekli adımlarla ilerlemeyi önerir.

\subsubsection{Tekli Dakikalarda Kalıp Değişimi (SMED)}

SMED, mümkün olan en kısa sürede üretim ekipmanını bir parçadan diğerine değiştirme sürecidir. Burada amaç, model değiştirme sürelerinin tek basamaklı sürelere düşürülmesidir [15]. SMED yaklaşımı temelde makine ve donanımın hazırlık sürelerini azaltmaya çalışır. Bunun yapılabilmesi için işgücünün yaptığı gereksiz hareketlerin ve hazırlık amacı ile makine üzerinde yapılan işlemlerin analiz edilmesi gerekir.

\subsubsection{Hücresel Üretim}

Hücresel üretim, üretim hücrelerinin kullanılmasını gerektirir. Üretim hücrelerinde, benzer ürünlerin üretimi için gerekli olan işgücü ve makinalar birbirine yakın olacak şekilde yerleştirilerek daha iyi bir performans elde edilmesi amaçlanmaktadır [16].

\subsubsection{Toplam Üretken Bakım (TPM)}

Aynı zamanda toplam üretken bakım olarak da adlandırılan Toplam Önleyici Bakım (TPM), makine arızalarının sayısını ve sürelerini azaltır.

\subsubsection{Tam Zamanında Üretim (JIT)}

Tam zamanında üretim, doğru ürünün doğru yerde doğru zamanda bulunmasını sağlayan bir malzeme yönetim sistemidir ve yalın üretimin temel bileşenlerinden biridir.

\subsubsection{Kanban}

Kanban, Japonca "kart" veya "görünür kayıt" anlamında olup, fabrika içinde üretimin akışını kontrol etmekte kullanılan kartları temsil eder.

\subsubsection{Dünya Klasında Üretim (WCM)}

Dünya klasında üretim sürekli iyileştirmeyi amaçlamaktadır (Şekil 1) [17]. Dünya klasında üretimde, iş güvenliği ve israf-kayıp analizine dikkat edilmektedir. Önceliklerin belirlenmesi için veri akışı israf-kayıp analizi ile belirlenmektedir. İsraflara ve kayıplara maliyet değerleri atanır, daha sonra kayıpların birbiriyle ilişkisi belirlenir. Böylece enerjinin doğru noktalara harcanması sağlanır [18].

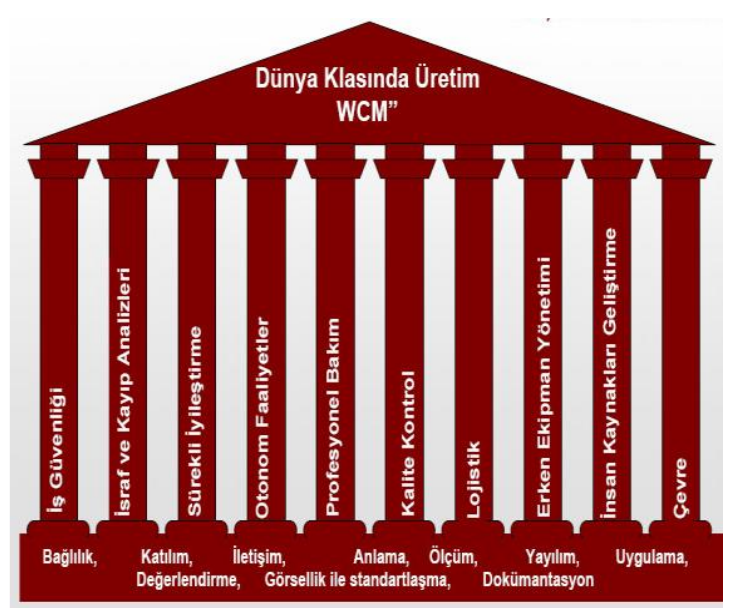

Şekil 1. Dünya klasında üretim modeli [17]

\subsubsection{Jidoka (Otonomasyon)}

Jidoka, makine/operatörlere normal dışı bir durum ortaya çıkması durumunda bu durumu belirleme ve işi derhal durdurma imkanını sağlamadır [15].

\subsubsection{Poka-Yoke (Hata Önleme)}

Poka-Yoke yöntemi, insan hatasını minimum yapmayı ve arızaya karşı emniyetli sistemler tasarlamayı amaçlamaktadır. Poka-Yoke ile 
insanların hata yapmasını önleyecek bir metot ya da alet geliştirilir. Bu teknik çoğunlukla üretim sistemlerinin hata oluşabilecek kısımlarına uygulanır ve genelde basit önlemleri içerir [19].

\subsubsection{Heijunka}

Heijunka, sabit bir zaman dilimi içinde üretim tipi ve miktarını seviyelendirmedir. Sonuç olarak stoklar, yatırım maliyetleri, işgücü ve bütün değer akışı boyunca üretim akış süresi en az seviyeye ulaşır [15].

\subsubsection{Hoshin Kanri}

Hoshin Kanri firma politikalarının ve hedeflerinin tüm çalışanlara yaymayı amaçlamaktadır. Böylece çalışanların bu politika ve hedeflerler ile uyumlu şekilde performans göstermesi sağlanmaktadır [20].

\subsubsection{Shojinka}

Shojinka, U tipi yerleşim planı kullanılarak fayda sağlamayan iş gücü hareketlerinin azaltılmasıdır. Shojinka ile makinelere parça yüklenmesi ve alınması mümkün olduğunca otomatikleştirilir. Böylece, bir işçinin birden fazla makineyi çalıştırabilmesine olanak oluşturulur [5].

\subsubsection{Değer Akış Haritaları}

Bir ürünü kavramdan seri üretime ve siparişten teslimata kadar getirmek için gerekli olan, değer yaratan ve değer yaratmayan eylemlerin hepsi değer akışı olarak tanımlanır. $\mathrm{Bu}$ eylemlere müşteriden gelen bilginin işlenmesi ve müşteriye giden yolda ürünü dönüştürmek için yapılan eylemler de dahildir [15]. Değer akışlarının haritalarının oluşturulması ise değer akışı haritalamadır. Değer akışı haritalama ile tüm çalışanların israfları görmeleri ve böylece bu israfları azalmak için çözüm yollarının bulunması sağlanmaktadır.

\subsubsection{4. $5 \mathrm{~S}$}

$5 S$; tertip, düzen ve temizlik için gerekli olan temel noktaların Japonca kelimelerinin baş harflerinden oluşturulan bir kavramdır. 5S tekniği (sınıflandırma, düzenleme, temizlik, standartlaşma, eğitim ve disiplin), çalışma alanının daha düzenli ve kullanılabilir olması için standartlaştırılmış uygulamalara dayanır. 5S, çalışma alanını düzenler ve gereksiz olan her şeyi azaltarak, sonuçta etkin bir çalışma ortamı sağlar.

\subsubsection{Görsel Fabrika (Görsel Yönetim)}

Bütün araçların, parçaların ve üretim sistemi performans göstergelerinin üretimin içindeki herkesin görüş alanında olacak şekilde konumlandırılmasıdır [15].

\section{METOT}

\subsection{Cronbach's Alpha Sayısına Göre Güvenilirlik Analizi}

Güvenilirlik analizi, ankete verilen yanıtların tutarlılığını ölçer. Güvenilirlik analizi için kullanılan temel analiz Cronbach's Alpha $(\alpha)$ değerinin bulunmasıdır ve $\alpha$ değerinin $0,7^{\prime}$ den büyük olması istenir [21].

\subsection{Bağımsız t-Testi}

Bağımsız t-testi, ile iki grubun ortalamaları karşılaştırılarak aradaki farkın rassal mı yoksa istatistiksel olarak mı anlamlı olduğuna karar verilir [22].

\subsection{Mann Whitney U-Testi}

Mann Whitney u testi, Student t testinin ön şartları yerine gelmediğinde kullanılan alternatif bir nonparametrik testtir [22].

\subsection{Korelasyon Analizi}

İki sayısal ölçüm arasında doğrusal bir ilişki olup olmadığını, varsa bu ilişkinin yönünü ve şiddetinin ne olduğunu belirlemek için kullanılan bir istatistiksel yöntemdir. Verilerin normal dağılıma sahip olmasi durumunda Pearson korelasyon katsayısı, verilerin normal dağılmadığı durumda ise Spearman Rank korelasyon katsayısı tercih edilir[22]. 


\section{BULGULAR VE TARTIŞMA}

Bu çalışmada 13 adet hipotez kurulmuştur. 13 adet hipotez için 30 adet firmanın 46 adet soruya verdiği cevaplar doğrultusunda otomotiv yan sanayi firmalarının yalın üretimi benimsemeleri ve yalın üretim tekniklerini uygulamaları incelenmiştir. Tüm hipotezler firma yaşları, sermaye yapıları, çalışan sayılarına bakılarak gruplandırılmış ve bağımsız t-testi, Mann Whitney U-testi ve korelasyon analizi yardımıyla analiz edilmiştir.

\section{Hipotezler:}

H1: Yalın üretim sistemini kullanan otomotiv yan sanayi firmaları yalın üretim sistemini ve yalın üretim uygulamalarını tam olarak özümsemiştir.

$\mathrm{H} 2$ : Yalın üretim uygulamalarından " $5 \mathrm{~s}$ " uygulaması tam olarak uygulanmış ve anlaşılmıştır.

H3: Yalın üretim uygulamalarından SMED uygulaması tam olarak uygulanmış ve anlaşılmıştır.

H4: Yalın üretim uygulamalarından KANBAN uygulaması tam olarak uygulanmış ve anlaşılmıştır.

H5: Yalın üretim uygulamalarından TPM uygulaması tam olarak uygulanmış ve anlaşılmıștır.

H6: Yalın üretim uygulamalarından hücresel imalat uygulaması tam olarak uygulanmış ve anlaşılmıştır.

H7: Yalın üretim uygulamalarından JIDOKA uygulaması tam olarak uygulanmış ve anlaşılmıştır.

H8: Yalın üretim uygulamalarından görsel fabrika uygulaması tam olarak uygulanmış ve anlaşılmıştır.

H9: Yalın üretim uygulamalarından POKEYOKE uygulaması tam olarak uygulanmış ve anlaşılmıştır.

H10: Yalın üretim uygulamalarından HEIJUNKA uygulaması tam olarak uygulanmış ve anlaşılmıştır.
H11: Yalın üretim uygulamalarından HOSHINKARNI uygulaması tam olarak uygulanmış ve anlaşılmıştır.

H12: Yalın üretim uygulamalarından SHOJINKA uygulaması tam olarak uygulanmış ve anlaşılmıştır.

H13: Yalın üretim uygulamalarından değer akış haritaları uygulaması tam olarak uygulanmış ve anlaşılmıştır.

\subsection{Güvenilirlik Analizi}

Tüm hipotezler için Cronbach's Alpha sayısına göre güvenilirlik analizi yapıllmıştır. Çizelge 1'de görüldüğü gibi bulunan $\alpha$ değerleri 0,7 'den büyük olduğundan anketin yüksek güvenilirliğe sahip olduğu söylenebilir.

Çizelge 1. Cronbach's alpha sayısına göre güvenilirlik analizi

\begin{tabular}{|c|c|}
\hline \multicolumn{2}{|c|}{ Güvenilirlik Analizi } \\
\hline Hipotezler & Cronbach's Alpha Değeri \\
\hline H1 & 0,717 \\
\hline H2 & 0,891 \\
\hline H3 & 0,939 \\
\hline H4 & 0,950 \\
\hline H5 & 0,846 \\
\hline H6 & 0,933 \\
\hline H7 & 0,770 \\
\hline H8 & 0,912 \\
\hline H9 & 0,885 \\
\hline H10 & 0,761 \\
\hline H11 & 0,744 \\
\hline H12 & 0,826 \\
\hline H13 & 0,953 \\
\hline
\end{tabular}

\subsection{Normallik Testi}

Her bir hipotez için elde edilen verilerin normal dağılıma uygun olup-olmadığı KolmogorovSmirnov testi ve Shapiro-Wilk testi kullanılarak belirlenmiştir. Test sonuçlarına göre H2, H3, H4, H6, H11 ve H12 hipotezlerinin normal dağılıma uyduğu (sigma değerleri $\geq 0,05$ ), diğer hipotezlerin ise uymadığı gözlemlenmiştir. 
Çizelge 2. Normallik testi sonuçları

\begin{tabular}{|c|c|c|c|c|c|c|}
\hline \multicolumn{9}{|c|}{ Normallik Testi } \\
\hline & \multicolumn{1}{|c|}{ Kolmogorov-Smirnov } & \multicolumn{3}{|c|}{ Shapiro-Wilk } \\
\hline & İst. & df & Sig. & İst. & df & Sig. \\
\hline Yalın & 0,16 & 30 & 0,033 & 0,91 & 30 & 0,019 \\
\hline 5s & 0,16 & 30 & 0,049 & 0,94 & 30 & 0,130 \\
\hline Smed & 0,13 & 30 & 0,189 & 0,94 & 30 & 0,114 \\
\hline Kanban & 0,13 & 30 & 0,147 & 0,93 & 30 & 0,057 \\
\hline Tpm & 0,19 & 30 & 0,007 & 0,90 & 30 & 0,011 \\
\hline Hücresel & 0,12 & 30 & 0,200 & 0,94 & 30 & 0,145 \\
\hline Jidoka & 0,19 & 30 & 0,004 & 0,90 & 30 & 0,010 \\
\hline Görsel & 0,28 & 30 & 0,000 & 0,85 & 30 & 0,001 \\
\hline Poke-yoke & 0,27 & 30 & 0,000 & 0,84 & 30 & 0,000 \\
\hline Heijunka & 0,19 & 30 & 0,004 & 0,91 & 30 & 0,019 \\
\hline Hos.-karn1 & 0,18 & 30 & 0,012 & 0,94 & 30 & 0,094 \\
\hline Shojıka & 0,11 & 30 & 0,200 & 0,95 & 30 & 0,293 \\
\hline Değerak1ş & 0,15 & 30 & 0,054 & 0,92 & 30 & 0,032 \\
\hline
\end{tabular}

\subsection{Firma Yaşına Göre Hipotezlerin Analizi}

Hipotezlerin analizi için, firma yaşı 20'den büyük ve firma yaşı 20'den küçük olacak şekilde gruplandırma yapılmıştır. Normal dağılıma uyan hipotezlerin analizi için t-testi, normal dağılıma uymayan hipotezlerin analizi için ise Mann Whitney U-testi kullanılmıştır. T-testi ve Mann Whitney U-testi sonuçlarına göre; firma yaşı ile hipotez grupları arasında anlamlı bir fark bulunmamıştır (Çizelge 3 ve Çizelge 4). Korelasyon analizi sonuçlarına bakıldığında ise sadece H10 hipotezi için firma yaşı ile hipotez grupları arasında zayıf bir korelasyon ilişkisi olduğu görülmüştür (Çizelge 5 ve Çizelge 6).

Çizelge 3. Firma yaşına göre t-testi

\begin{tabular}{|c|c|c|c|c|c|c|c|c|}
\hline & & $\mathrm{F}$ & Sig. & $\mathrm{t}$ & df & $\begin{array}{c}\text { Sig. } \\
\text { (2-tailed) }\end{array}$ & $\begin{array}{l}\text { Ort. } \\
\text { fark }\end{array}$ & $\begin{array}{l}\text { Std. Hata } \\
\text { fark }\end{array}$ \\
\hline \multirow[t]{2}{*}{ Yalın } & Var. eşit & 1,311 & 0,262 & $-0,399$ & 28 & 0,693 & $-0,085$ & 0,214 \\
\hline & Varyanslar eşit değil & & & $-0,405$ & 27,85 & 0,689 & $-0,085$ & 0,211 \\
\hline \multirow[t]{2}{*}{$5 \mathrm{~s}$} & Var. eşit & 0,011 & 0,918 & 0,449 & 28 & 0,657 & 0,129 & 0,288 \\
\hline & Varyanslar eşit değil & & & 0,447 & 26,91 & 0,659 & 0,129 & 0,289 \\
\hline \multirow[t]{2}{*}{ Smed } & Var. eşit & 8,830 & 0,006 & $-0,122$ & 28 & 0,904 & $-0,055$ & 0,451 \\
\hline & Varyanslar eşit değil & & & $-0,118$ & 20,08 & 0,908 & $-0,055$ & 0,467 \\
\hline \multirow[t]{2}{*}{ Kanban } & Var. eşit & 0,004 & 0,951 & 0,788 & 28 & 0,437 & 0,357 & 0,453 \\
\hline & Varyanslar eşit değil & & & 0,783 & 26,64 & 0,440 & 0,357 & 0,456 \\
\hline \multirow[t]{2}{*}{ Tpm } & Var. eşit & 0,006 & 0,940 & $-0,516$ & 28 & 0,610 & $-0,223$ & 0,432 \\
\hline & Varyanslar eşit değil & & & $-0,517$ & 27,63 & 0,610 & $-0,223$ & 0,432 \\
\hline \multirow[t]{2}{*}{ Hücresel } & Var. eşit & 1,128 & 0,297 & $-0,378$ & 28 & 0,708 & $-0,142$ & 0,377 \\
\hline & Varyanslar eşit değil & & & $-0,383$ & 27,94 & 0,705 & $-0,142$ & 0,372 \\
\hline \multirow[t]{2}{*}{ Jidoka } & Var. eşit & 4,682 & 0,039 & 0,772 & 28 & 0,447 & 0,306 & 0,397 \\
\hline & Varyanslar eşit değil & & & 0,753 & 22,43 & 0,460 & 0,306 & 0,407 \\
\hline \multirow[t]{2}{*}{ Görsel } & Var. eşit & 2,246 & 0,145 & 0,121 & 28 & 0,905 & 0,040 & 0,332 \\
\hline & Varyanslar eşit değil & & & 0,118 & 24,08 & 0,907 & 0,040 & 0,339 \\
\hline \multirow[t]{2}{*}{ Poke-yoke } & Var. eşit & 2,994 & 0,095 & 0,339 & 28 & 0,737 & 0,110 & 0,324 \\
\hline & Varyanslar eşit değil & & & 0,327 & 19,47 & 0,747 & 0,110 & 0,336 \\
\hline \multirow[t]{2}{*}{ Heijunka } & Var. eşit & 0,126 & 0,725 & $-1,262$ & 28 & 0,217 & $-0,486$ & 0,385 \\
\hline & Varyanslar eşit değil & & & $-1,249$ & 25,92 & 0,223 & $-0,486$ & 0,389 \\
\hline \multirow[t]{2}{*}{ Hos.-karni } & Var. eşit & 3,791 & 0,062 & $-0,872$ & 28 & 0,391 & $-0,308$ & 0,353 \\
\hline & Varyanslar eşit değil & & & $-0,849$ & 22,19 & 0,405 & $-0,308$ & 0,362 \\
\hline \multirow[t]{2}{*}{ Shojika } & Var. eşit & 1,400 & 0,247 & $-0,728$ & 28 & 0,473 & $-0,254$ & 0,349 \\
\hline & Var. eşit değil & & & $-0,714$ & 24,13 & 0,482 & $-0,254$ & 0,356 \\
\hline \multirow[t]{2}{*}{ Değerakış } & Var. eşit & 1,870 & 0,182 & $-0,273$ & 28 & 0,787 & $-0,116$ & 0,425 \\
\hline & Var. eşit değil & & & $-0,269$ & 24,82 & 0,790 & $-0,116$ & 0,431 \\
\hline
\end{tabular}


Çizelge 4. Firma yaşına göre Mann-Whitney-U testi

\begin{tabular}{|l|l|l|l|}
\hline Boş Hipotezler & Test & Sig. & Karar \\
\hline Firma yaş1 ile H1 arasında anlamlı bir fark yoktur & Mann-Whitney-U Testi & 0,984 & Boş hipotezi kabul et. \\
\hline Firma yaşı ile H2 arasında anlamlı bir fark yoktur & Mann-Whitney-U Testi & 0,822 & Boş hipotezi kabul et. \\
\hline Firma yaşı ile H3 arasında anlamlı bir fark yoktur & Mann-Whitney-U Testi & 1,000 & Boş hipotezi kabul et. \\
\hline Firma yaş1 ile H4 arasında anlamlı bir fark yoktur & Mann-Whitney-U Testi & 0,552 & Boş hipotezi kabul et. \\
\hline Firma yaşı ile H5 arasında anlamlı bir fark yoktur & Mann-Whitney-U Testi & 0,608 & Boş hipotezi kabul et. \\
\hline Firma yaşı ile H6 arasında anlamlı bir fark yoktur & Mann-Whitney-U Testi & 0,886 & Boş hipotezi kabul et. \\
\hline Firma yaş1 ile H7 arasında anlamlı bir fark yoktur & Mann-Whitney-U Testi & 0,637 & Boş hipotezi kabul et. \\
\hline Firma yaşı ile H8 arasında anlamlı bir fark yoktur & Mann-Whitney-U Testi & 0,790 & Boş hipotezi kabul et. \\
\hline Firma yaş1 ile H9 arasında anlamlı bir fark yoktur & Mann-Whitney-U Testi & 0,667 & Boş hipotezi kabul et. \\
\hline Firma yaş1 ile H10 arasında anlamlı bir fark yoktur & Mann-Whitney-U Testi & 0,224 & Boş hipotezi kabul et. \\
\hline Firma yaşı ile H11 arasında anlamlı bir fark yoktur & Mann-Whitney-U Testi & 0,448 & Boş hipotezi kabul et. \\
\hline Firma yaş1 ile H12 arasında anlamlı bir fark yoktur & Mann-Whitney-U Testi & 0,448 & Boş hipotezi kabul et. \\
\hline Firma yaş1 ile H13 arasında anlamlı bir fark yoktur & Mann-Whitney-U Testi & 0,667 & Boş hipotezi kabul et. \\
\hline
\end{tabular}

Çizelge 5. Firma yaşına göre Pearson Korelasyon Analizi

\begin{tabular}{|c|c|c|c|}
\hline & & Kurulu Tarihi & Kanban \\
\hline \multirow[t]{3}{*}{ Kuruluş Tarihi } & Pearson Correlation & 1,000 & $-0,147$ \\
\hline & Sig. (2-tailed) & & 0,437 \\
\hline & $\mathrm{N}$ & 30 & 30 \\
\hline \multirow[t]{3}{*}{ Kanban } & Pearson Correlation & $-0,147$ & 1,000 \\
\hline & Sig. (2-tailed) & 0,437 & \\
\hline & $\mathrm{N}$ & 30 & 30 \\
\hline & & Kurulu Tarihi & Smed \\
\hline \multirow[t]{3}{*}{ Kuruluş Tarihi } & Pearson Correlation & 1,000 & 0,023 \\
\hline & Sig. (2-tailed) & & 0,904 \\
\hline & $\mathrm{N}$ & 30 & 30 \\
\hline \multirow[t]{3}{*}{ Smed } & Pearson Correlation & 0,023 & 1,000 \\
\hline & Sig. (2-tailed) & 0,904 & \\
\hline & $\mathrm{N}$ & 30 & 30 \\
\hline \multirow{4}{*}{ Kuruluş Tarihi } & & Kurulu Tarihi & Hos.-karni \\
\hline & Pearson Correlation & 1,000 & 0,163 \\
\hline & Sig. (2-tailed) & & 0,391 \\
\hline & $\mathrm{N}$ & 30 & 30 \\
\hline \multirow{3}{*}{ Hos.-karni } & Pearson Correlation & 0,163 & 1,000 \\
\hline & Sig. (2-tailed) & 0,391 & \\
\hline & $\mathrm{N}$ & 30 & 30 \\
\hline & & Kurulu Tarihi & $5 \mathrm{~s}$ \\
\hline \multirow[t]{3}{*}{ Kuruluş Tarihi } & Pearson Correlation & 1,000 & $-0,085$ \\
\hline & Sig. (2-tailed) & & 0,657 \\
\hline & $\mathrm{N}$ & 30 & 30 \\
\hline \multirow[t]{3}{*}{$5 \mathrm{~s}$} & Pearson Correlation & $-0,085$ & 1,000 \\
\hline & Sig. (2-tailed) & 0,657 & \\
\hline & $\mathrm{N}$ & 30 & 30 \\
\hline & & Kurulu Tarihi & Hücresel \\
\hline \multirow[t]{3}{*}{ Kurulu Tarihi } & PearsonCorrelation & 1,000 & 0,071 \\
\hline & Sig. (2-tailed) & & 0,708 \\
\hline & $\mathrm{N}$ & 30 & 30 \\
\hline \multirow[t]{3}{*}{ Hücresel } & PearsonCorrelation & 0,071 & 1,000 \\
\hline & Sig. (2-tailed) & 0,708 & \\
\hline & $\mathrm{N}$ & 30 & 30 \\
\hline \multirow{4}{*}{ KurulusTarihi } & & KurulusTarihi & Shojika \\
\hline & PearsonCorrelation & 1,000 & 0,136 \\
\hline & Sig. (2-tailed) & & 0,473 \\
\hline & $\mathrm{N}$ & 30 & 30 \\
\hline \multirow[t]{3}{*}{ Shojika } & PearsonCorrelation & 0,136 & 1,000 \\
\hline & Sig. (2-tailed) & 0,473 & \\
\hline & $\mathrm{N}$ & 30 & 30 \\
\hline
\end{tabular}


Çizelge 6. Firma yaşına göre Spearman Korelasyon Analizi

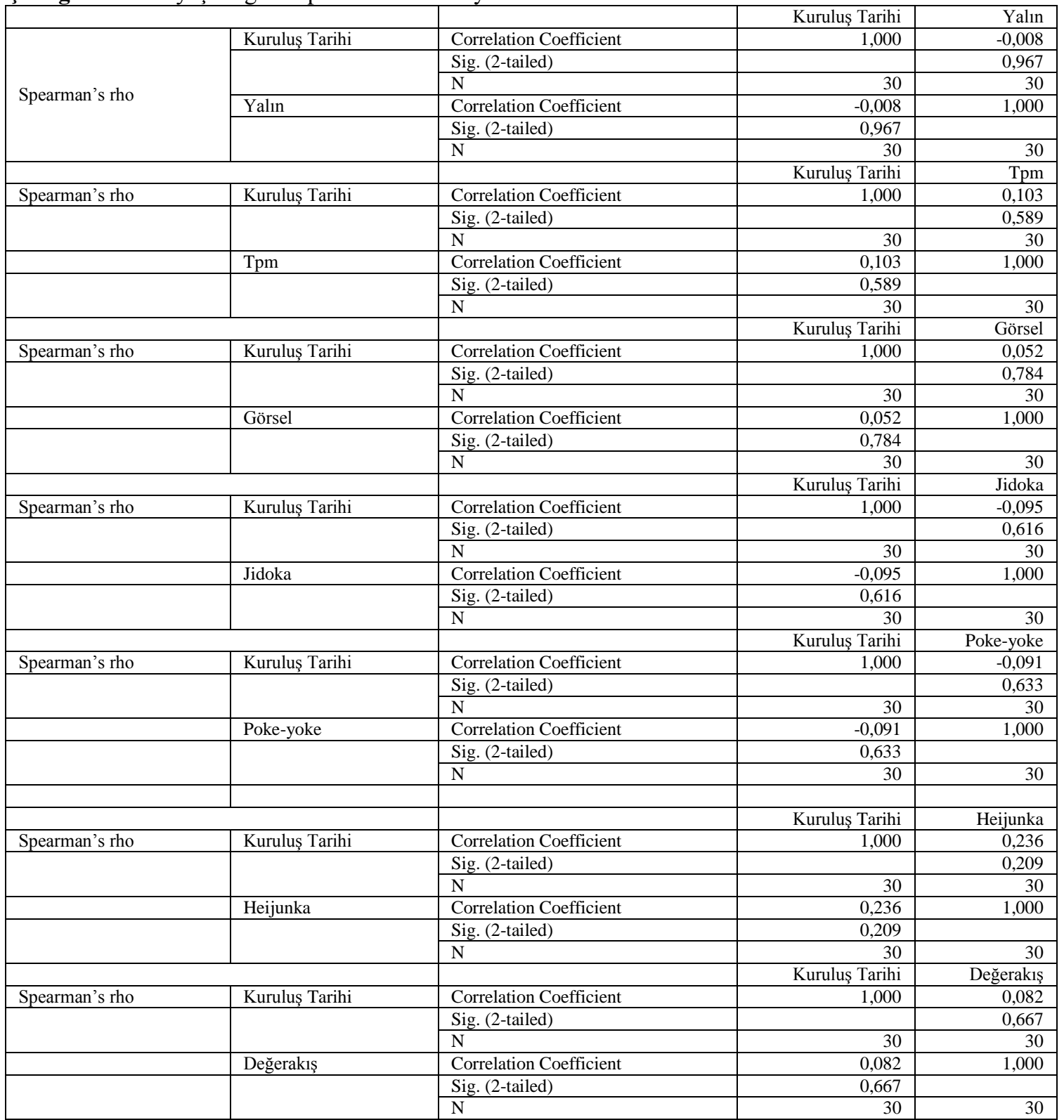

\subsection{Sermaye Yapısına Göre Hipotezlerin Analizi}

Hipotezlerin analizi için, sermaye yapısı yerli sermaye ve yabancı sermaye olacak şekilde gruplandırma yapılmıştır. Normal dağılıma uyan hipotezlerin analizi için t-testi, normal dağılıma uymayan hipotezlerin analizi için ise Mann Whitney U-testi kullanılmıştır. T-testi ve Mann Whitney U-testi sonuçlarına göre; sermaye yapısı ile hipotez grupları arasında anlamlı bir fark bulunmamıştır (H1 hipotezi hariç). H1 hipotezi için Mann Whitney U-testi uygulandığında sigma değerinin 0,05 değerinden küçük olduğu 
görülmüştür. $\mathrm{Bu}$ nedenle, sermaye yapısı ile $\mathrm{H} 1$ hipotezi grupları arasında anlamlı bir fark olduğu söylenebilir. Korelasyon analizi sonuçlarına bakıldığında ise $\mathrm{H} 1$ ve $\mathrm{H} 2$ hipotezlerinde sermaye yapıs1 ile hipotez grupları arasında orta bir korelasyon ilişkisi olduğu, $\mathrm{H} 4$ ve $\mathrm{H} 7$ hipotezlerinde ise sermaye yapısı ile hipotez grupları arasında zayıf bir korelasyon ilişkisi olduğu görülmüştür.

\section{5. Çalışan Sayısına Göre Hipotezlerin Analizi}

Hipotezlerin analizi için, çalışan sayısı 130'dan büyük ve çalışan sayısı 130'dan küçük olacak şekilde gruplandırma yapılmıştır. Normal dağılıma uyan hipotezlerin analizi için t-testi, normal dağılıma uymayan hipotezlerin analizi için ise Mann Whitney U-testi kullanılmıştır. T-testi ve Mann Whitney U-testi sonuçlarına göre; çalışan sayısı ile hipotez grupları arasında anlamlı bir fark bulunmamıştır. Korelasyon analizi sonuçlarına bakıldığında ise $\mathrm{H} 1, \mathrm{H} 2, \mathrm{H} 3, \mathrm{H} 4, \mathrm{H} 7, \mathrm{H} 8$ ve $\mathrm{H} 9$ hipotezleri için çalışan sayısı ile hipotez grupları arasında zayıf bir korelasyon ilişkisi olduğu görülmüştür.

\subsection{Uygulamaların Kendi Aralarındaki Korelasyon İlişkisi}

Otomotiv yan sanayi firmalarının yalın üretimi benimsemeleri ve yalın üretim tekniklerini uygulamalarının incelenmesi için oluşturulan 13 hipotezin birbiri ile ilişkilerini incelemek için korelasyon analizi yapılmıştır (Şekil 2 ve Şekil 3). Şekil 4 ve Şekil 5'de yüksek korelasyon sarı ile, orta korelasyon yeşil ile ve zayıf korelasyon turuncu ile gösterilmiştir.

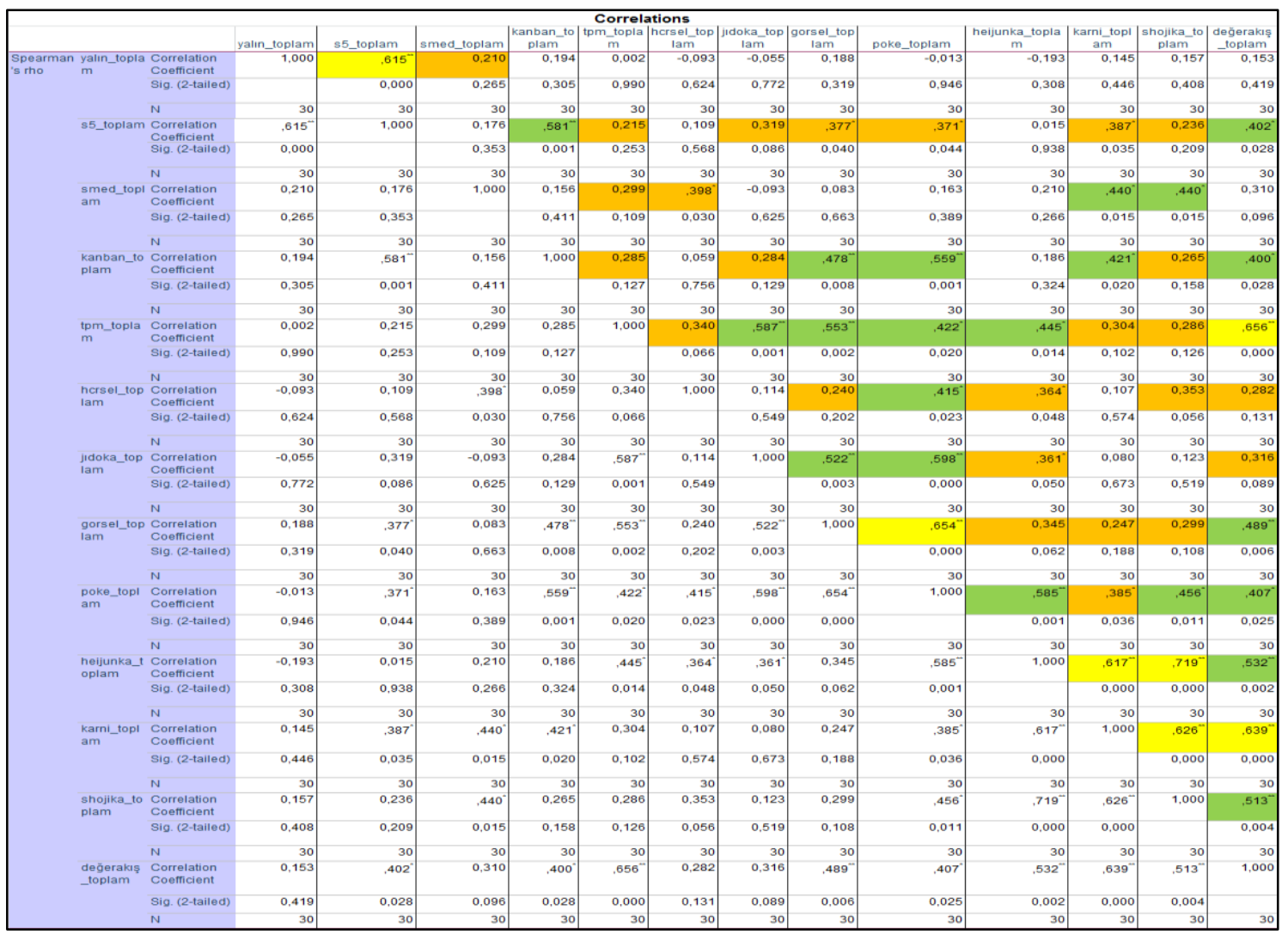

Şekil 2. Yalın üretim teknikleri için sperman korelasyon analizi 


\begin{tabular}{|c|c|c|c|c|c|c|c|c|c|c|c|c|c|c|}
\hline & & yalın_toplam & s5_toplam & $\begin{array}{c}\begin{array}{c}\text { smed_topl } \\
\text { am }\end{array} \\
\end{array}$ & $\begin{array}{c}\text { kanban_to } \\
\text { plam }\end{array}$ & $\begin{array}{c}\text { tpm_topla } \\
\text { m }\end{array}$ & $\begin{array}{c}\text { hcrsel_top } \\
\text { lam }\end{array}$ & jidoka_toplam & gorsel_toplam & $\begin{array}{c}\text { poke_topl } \\
\text { am }\end{array}$ & \begin{tabular}{|c|}
$\begin{array}{c}\text { heijunka_t } \\
\text { oplam }\end{array}$ \\
\end{tabular} & \begin{tabular}{|c|}
$\begin{array}{c}\text { karni_topl } \\
\text { am }\end{array}$ \\
\end{tabular} & \begin{tabular}{|c|}
$\begin{array}{c}\text { shojika_to } \\
\text { plam }\end{array}$ \\
\end{tabular} & $\begin{array}{c}\text { değerakış } \\
\text { _toplam }\end{array}$ \\
\hline \multirow[t]{3}{*}{ yalın_toplam } & $\begin{array}{l}\text { Pearson } \\
\text { Correlation }\end{array}$ & 1 & $.498^{-}$ & 0,225 & 0,136 & $-0,026$ & $-0,128$ & $-0,114$ & 0,137 & 0,013 & $-0,222$ & 0,120 & 0,171 & 0,095 \\
\hline & Sig. (2-tailed) & & 0,005 & 0,233 & 0,475 & 0,894 & 0,501 & 0,550 & 0,469 & 0,947 & 0,239 & 0,527 & 0,366 & 0,617 \\
\hline & $\mathrm{N}$ & 30 & 30 & 30 & 30 & 30 & 30 & 30 & 30 & 30 & 30 & 30 & 30 & 30 \\
\hline \multirow[t]{3}{*}{ s5_toplam } & $\begin{array}{l}\text { Pearson } \\
\text { Correlation }\end{array}$ & $.498^{-1}$ & 1 & 0,141 &, $557^{-1}$ & 0,228 & 0,177 &, $378^{\circ}$ &, $457^{\circ}$ & 0,361 & $-0,006$ &, $363^{\circ}$ & 0,245 & $441^{\circ}$ \\
\hline & Sig. (2-tailed) & 0,005 & & 0,456 & 0,001 & 0,226 & 0,349 & 0,040 & 0,011 & 0,050 & 0,977 & 0,049 & 0,193 & 0,015 \\
\hline & $\mathrm{N}$ & 30 & 30 & 30 & 30 & 30 & 30 & 30 & 30 & 30 & 30 & 30 & 30 & 30 \\
\hline \multirow[t]{3}{*}{$\begin{array}{l}\text { smed_topla } \\
\mathrm{m}\end{array}$} & $\begin{array}{l}\text { Pearson } \\
\text { Correlation }\end{array}$ & 0,225 & 0,141 & 1 & 0,153 & 0,309 & 0,315 & 0,003 & 0,099 & 0,303 & 0,205 &, $472^{-}$ & $.454^{\circ}$ & 0,292 \\
\hline & Sig. (2-tailed) & 0,233 & 0,456 & & 0,419 & 0,097 & 0,090 & 0,987 & 0,602 & 0,104 & 0,276 & 0,008 & 0,012 & 0,117 \\
\hline & $\mathrm{N}$ & 30 & 30 & 30 & 30 & 30 & 30 & 30 & 30 & 30 & 30 & 30 & 30 & 30 \\
\hline \multirow[t]{3}{*}{$\begin{array}{l}\text { kanban_topl } \\
\text { am }\end{array}$} & $\begin{array}{l}\text { Pearson } \\
\text { Correlation }\end{array}$ & 0,136 & $.557^{-1}$ & 0,153 & 1 & 0,323 & 0,069 & 0,344 &, $368^{\circ}$ &, $531^{-}$ & 0,159 & $.415^{\circ}$ & 0,298 & $.447^{\circ}$ \\
\hline & Sig. (2-tailed) & 0,475 & 0,001 & 0,419 & & 0,082 & 0,715 & 0,063 & 0,045 & 0,003 & 0,401 & 0,022 & 0,110 & 0,013 \\
\hline & $\mathrm{N}$ & 30 & 30 & 30 & 30 & 30 & 30 & 30 & 30 & 30 & 30 & 30 & 30 & 30 \\
\hline \multirow[t]{3}{*}{ tpm_toplam } & $\begin{array}{l}\text { Pearson } \\
\text { Correlation }\end{array}$ & $-0,026$ & 0,228 & 0,309 & 0,323 & 1 & 0,326 & $.672^{-}$ & $.624^{-}$ &, $542^{-}$ &, $429^{\circ}$ & 0,353 & 0,310 & $.659^{-}$ \\
\hline & Sig. (2-tailed) & 0,894 & 0,226 & 0,097 & 0,082 & & 0,078 & 0,000 & 0,000 & 0,002 & 0,018 & 0,055 & 0,096 & 0,000 \\
\hline & $\mathrm{N}$ & 30 & 30 & 30 & 30 & 30 & 30 & 30 & 30 & 30 & 30 & 30 & 30 & 30 \\
\hline \multirow[t]{3}{*}{$\begin{array}{l}\text { hcrsel_topla } \\
\text { m }\end{array}$} & $\begin{array}{l}\text { Pearson } \\
\text { Correlation }\end{array}$ & $-0,128$ & 0,177 & 0,315 & 0,069 & 0,326 & 1 & 0,248 & 0,329 & $396^{\circ}$ & $384^{-1}$ & 0,155 & $.380^{\circ}$ & 0,223 \\
\hline & Sig. (2-tailed) & 0,501 & 0,349 & 0,090 & 0,715 & 0,078 & & 0,187 & 0,076 & 0,030 & 0,036 & 0,413 & 0,038 & 0,236 \\
\hline & $\mathrm{N}$ & 30 & 30 & 30 & 30 & 30 & 30 & 30 & 30 & 30 & 30 & 30 & 30 & 30 \\
\hline \multirow[t]{3}{*}{$\begin{array}{l}\text { jidoka_topla } \\
\text { m }\end{array}$} & $\begin{array}{l}\text { Pearson } \\
\text { Correlation }\end{array}$ & $-0,114$ & $378^{\circ}$ & 0,003 & 0,344 & $672^{-1}$ & 0,248 & 1 & $.656^{-1}$ & $661^{-1}$ & $.438^{\circ}$ & 0,192 & 0,192 & $450^{\circ}$ \\
\hline & Sig. (2-tailed) & 0,550 & 0,040 & 0,987 & 0,063 & 0,000 & 0,187 & & 0,000 & 0,000 & 0,015 & 0,309 & 0,310 & 0,013 \\
\hline & $\mathrm{N}$ & 30 & 30 & 30 & 30 & 30 & 30 & 30 & 30 & 30 & 30 & 30 & 30 & 30 \\
\hline \multirow[t]{3}{*}{$\begin{array}{l}\text { gorsel_topla } \\
\mathrm{m}\end{array}$} & $\begin{array}{l}\text { Pearson } \\
\text { Correlation }\end{array}$ & 0,137 & $.457^{\circ}$ & 0,099 & $368^{\circ}$ & $624^{4}$ & 0,329 &, $656^{4}$ & 1 &, $752^{-}$ & 0,356 & 0,309 & 0,342 &, $567^{-}$ \\
\hline & Sig. (2-tailed) & 0,469 & 0,011 & 0,602 & 0,045 & 0,000 & 0,076 & 0,000 & & 0,000 & 0,053 & 0,097 & 0,064 & 0,001 \\
\hline & $\mathrm{N}$ & 30 & 30 & 30 & 30 & 30 & 30 & 30 & 30 & 30 & 30 & 30 & 30 & 30 \\
\hline \multirow[t]{3}{*}{$\begin{array}{l}\text { poke_topla } \\
\text { m }\end{array}$} & $\begin{array}{l}\text { Pearson } \\
\text { Correlation }\end{array}$ & 0,013 & 0,361 & 0,303 & $.531^{-1}$ &, $542^{-1}$ & $396^{\circ}$ & ,661 &, $752^{-}$ & 1 & $.558^{-}$ & $.496^{-}$ & $.493^{-}$ & $524^{-}$ \\
\hline & Sig. (2-tailed) & 0,947 & 0,050 & 0,104 & 0,003 & 0,002 & 0,030 & 0,000 & 0,000 & & 0,001 & 0,005 & 0,006 & 0,003 \\
\hline & $N$ & 30 & 30 & 30 & 30 & 30 & 30 & 30 & 30 & 30 & 30 & 30 & 30 & 30 \\
\hline \multirow[t]{3}{*}{$\begin{array}{l}\text { heijunka_to } \\
\text { plam }\end{array}$} & $\begin{array}{l}\text { Pearson } \\
\text { Correlation }\end{array}$ & $-0,222$ & $-0,006$ & 0,205 & 0,159 &, $429^{\circ}$ &, $384^{\circ}$ & $.438^{\circ}$ & 0,356 &, $558^{-1}$ & 1 & $.617^{-1}$ &, $695^{-1}$ & $506^{-}$ \\
\hline & Sig. (2-tailed) & 0,239 & 0,977 & 0,276 & 0,401 & 0,018 & 0,036 & 0,015 & 0,053 & 0,001 & & 0,000 & 0,000 & 0,004 \\
\hline & $\mathrm{N}$ & 30 & 30 & 30 & 30 & 30 & 30 & 30 & 30 & 30 & 30 & 30 & 30 & 30 \\
\hline \multirow[t]{3}{*}{$\begin{array}{l}\text { karni_topla } \\
\text { m }\end{array}$} & $\begin{array}{l}\text { Pearson } \\
\text { Correlation }\end{array}$ & 0,120 &, $363^{\circ}$ & $.472^{-1}$ & $.415^{\circ}$ & 0,353 & 0,155 & 0,192 & 0,309 &, $496^{-1}$ &, $617^{-1}$ & 1 & $597^{-1}$ & $665^{-}$ \\
\hline & Sig. (2-tailed) & 0,527 & 0,049 & 0,008 & 0,022 & 0,055 & 0,413 & 0,309 & 0,097 & 0,005 & 0,000 & & 0,000 & 0,000 \\
\hline & $\mathrm{N}$ & 30 & 30 & 30 & 30 & 30 & 30 & 30 & 30 & 30 & 30 & 30 & 30 & 30 \\
\hline \multirow[t]{3}{*}{$\begin{array}{l}\text { shojika_topl } \\
\text { am }\end{array}$} & $\begin{array}{l}\text { Pearson } \\
\text { Correlation }\end{array}$ & 0,171 & 0,245 & $.454^{\circ}$ & 0,298 & 0,310 & $380^{\circ}$ & 0,192 & 0,342 & $.493^{-1}$ &, $695^{-1}$ &, $597^{-1}$ & 1 & $528^{-}$ \\
\hline & Sig. (2-tailed) & 0,366 & 0,193 & 0,012 & 0,110 & 0,096 & 0,038 & 0,310 & 0,064 & 0,006 & 0,000 & 0,000 & & 0,003 \\
\hline & $\mathrm{N}$ & 30 & 30 & 30 & 30 & 30 & 30 & 30 & 30 & 30 & 30 & 30 & 30 & 30 \\
\hline \multirow[t]{3}{*}{$\begin{array}{l}\text { değerakış_t } \\
\text { oplam }\end{array}$} & $\begin{array}{l}\text { Pearson } \\
\text { Correlation }\end{array}$ & 0,095 &, $441^{\circ}$ & 0,292 & ,447 & $659^{-}$ & 0,223 &, $450^{\circ}$ & $.567^{-1}$ & $524^{-1}$ & $.506^{-1}$ &, $665^{-}$ & $.528^{-1}$ & 1 \\
\hline & Sig. (2-tailed) & 0,617 & 0,015 & 0,117 & 0,013 & 0,000 & 0,236 & 0,013 & 0,001 & 0,003 & 0,004 & 0,000 & 0,003 & \\
\hline & $\mathrm{N}$ & 30 & 30 & 30 & 30 & 30 & 30 & 30 & 30 & 30 & 30 & 30 & 30 & 30 \\
\hline
\end{tabular}

Şekil 3. Yalın üretim teknikleri için pearson korelasyon analizi

H2 Hipotezinin H4 hipoteziyle kiyaslanması sonucu Pearson korelasyon değeri 0,557 ve orta korelasyon ilişkisi bulunmaktadır. H4 Hipotezinin H11 hipoteziyle kıyaslanması sonucu Pearson korelasyon değeri 0,415 ve orta korelasyon ilişkisi bulunmaktadır. H11 Hipotezinin H12 hipoteziyle kıyaslanması sonucu Pearson korelasyon değeri 0,597 ve orta korelasyon bulunmaktadır. H5 Hipotezinin H7 ve H8 hipotezleriyle kiyaslanması sonucu Spearman's korelasyon değerleri sırasıyla
0,587 ve 0,553 bulunmuştur. Dolayısı ile orta korelasyon söz konusudur. H5 Hipotezinin H13 hipoteziyle kiyaslanması sonucu Spearman's korelasyon değeri 0,656 bulunmuştur ve yüksek korelasyon söz konusudur. H8 Hipotezinin H9 hipoteziyle kiyaslanması sonucu Spearman's korelasyon değeri 0,654 bulunmuştur ve yüksek korelasyon söz konusudur. H7 ile H8-9, H8 ile H13, H9 ile $\mathrm{H} 10$ ve $\mathrm{H} 10$ ile $\mathrm{H} 13$ hipotezleri arasında orta korelasyon bulunmuştur. 


\section{SONUÇLAR}

Yapılan tüm analizler sonucunda 13 hipotez için 30 adet firmanın 46 adet soruya verdiği cevaplar doğrultusunda incelenen otomotiv yan sanayi firmalarının yalın üretim tekniklerini aktif şekilde uyguladıkları görülmektedir. Anket sonuçlarının tanımlayıcı istatistikleri Çizelge 7'de sunulmuştur. Firmaların yaşlarına, çalışan sayılarına, sermaye yapısına göre oluşturulan gruplar ile yalın üretim tekniklerini uygulamaları arasında ilişki olup olmadığı Bağımsız-t testi, Mann-Whitney-U testi ve korelasyon analizi yardımıyla incelenmiştir. Analiz sonucunda yalın üretim teknikleri uygulamaları ile bazı hipotez grupları arasında orta ve zayıf korelasyona rastlanmış fakat aralarında firma yaşı, çalışan sayısı ve sermaye yapısına göre anlamlı ilişki bulunamamıştır. Sonuç olarak; firmalar yalın üretim uygulanışı ve yalın üretim uygulamalarını önemli bulmuş ve aktif bir şekilde kullandıklarını verdikleri cevaplarla göstermişlerdir.

Çizelge 7. Tanımlayıcı İstatistikler

\begin{tabular}{|l|c|c|c|c|c|c|c|}
\hline & N & En az & $\begin{array}{c}\text { En } \\
\text { çok }\end{array}$ & Ort. & $\begin{array}{c}\text { Std. } \\
\text { Sapma }\end{array}$ & Carpıklık & Basıklık \\
\hline Yalın & 30 & 2,6 & 4,8 & 3,84 & 0,57 & $-0,78$ & 0,08 \\
\hline 5 s & 30 & 2 & 4,83 & 3,7 & 0,77 & $-0,14$ & $-0,74$ \\
\hline Smed & 30 & 1 & 5 & 2,74 & 1,21 & 0,15 & $-1,02$ \\
\hline Kanban & 30 & 1 & 5 & 3,08 & 1,23 & $-0,24$ & $-0,99$ \\
\hline Tpm & 30 & 1,5 & 5 & 3,41 & 1,16 & $-0,23$ & -1 \\
\hline Hücresel & 30 & 1,25 & 5 & 3,44 & 1,01 & $-0,29$ & 0,42 \\
\hline Jidoka & 30 & 1 & 5 & 3,54 & 1,07 & $-0,69$ & 0,03 \\
\hline Görsel & 30 & 2 & 5 & 3,95 & 0,89 & $-0,88$ & 0,03 \\
\hline Poke-yoke & 30 & 1 & 5 & 3,67 & 0,87 & $-1,21$ & 2,2 \\
\hline Heijunka & 30 & 1 & 4,5 & 2,88 & 1,06 & $-0,15$ & $-1,27$ \\
\hline Hos.-karni & 30 & 1 & 5 & 2,8 & 0,96 & 0,08 & $-0,28$ \\
\hline Shojika & 30 & 1,25 & 4,75 & 3,02 & 0,94 & 0,06 & $-0,96$ \\
\hline Değerakış & 30 & 1,33 & 5 & 3,2 & 1,14 & $-0,2$ & $-1,23$ \\
\hline
\end{tabular}

Ayrıca tüm hipotezlerin birbiri ile olan korelasyon analizi sonuçlarına bakıldığında, yalın üretim teknikleri uygulamalarının birbiriyle ilişkili olduğu sonucuna ulaşılmıştır. Firmaların yalın üretim tekniklerinin çoğunu birlikte kullanması gerektiğini ön görmüş ve verdikleri cevaplarla uygulanan testlerle bu düşünce desteklenmiştir.

\section{KAYNAKLAR}

1. Özgiray, S., 2003. Otomotiv Sektöründe Yalın Üretim Sistemi ve Bir İşletmeye Uygulanması. Uludağ Üniversitesi Yüksek Lisans Tezi, Bursa.

2. Arslan, S., 2008. Yalın Üretim ve MAN Türkiye A.Ş.'de Örnek Bir Yalın Üretim Uygulaması. Gazi Üniversitesi Yüksek Lisans Tezi, Ankara.

3. Çobanoğlu, S., 2011. Yalın Üretim Sisteminin Otomotiv Sektöründe Uygulaması. Sakarya Üniversitesi Yüksek Lisans Tezi, Sakarya.

4. Küçükuysal, K., 2012. Otomotiv Yan Sanayi Sektöründe ERP ve Yalın Üretim Analizi. İTÜ Yüksek Lisans Tezi, İstanbul.

5. Bulut, S., 2012. Beyaz Eşya Yan Sanayi Sektöründe ERP ve Yalın Üretim Olgunluğu Analizi ve Otomotiv Yan Sanayi ile Kıyaslama. İTÜ Yüksek Lisans Tezi, İstanbul.

6. Gönen, K., 2013. Otomotiv Endüstrisinde Yalın Üretim ve Eşzamanlı Mühendislik Yaklaşımıyla Değer Akış Haritalandırma. Uludağ Üniversitesi Yüksek Lisans Tezi, Bursa.

7. Özçelik, T.Ö., Cinoğlu, F., 2013. Yalın Felsefe ve Bir Otomotiv Yan Sanayi Uygulamas1. İstanbul Ticaret Üniversitesi Fen Bilimleri Dergisi, 23, 79-101.

8. Uçan, K., 2014. Otomotiv Yan Sanayisinde Malzeme Besleme Sisteminin Yalın Üretim Yaklaşımıyla Yeniden Tasarlanması ve Bir Uygulama. İTÜ Yüksek Lisans Tezi, İstanbul.

9. Belekoukias, I. , Garza-Reyes, J., Kumar, V., 2014. The Impact of Lean Methods and Tools on the Operational Performance of Manufacturing Organizations. International Journal of Production Research, 52(18), 5346-5366.

10. Kılıç, A., 2016. Otomotiv Yan Sanayinde Yalın Üretim Uygulamas1. İstanbul Ticaret Üniversitesi Yüksek Lisans Tezi, İstanbul.

11. Adalı, M.R., Kiraz, A., Akyüz, U., 2017. Yalın Üretime Geçiş Sürecinde Değer Akışı Haritalama Tekniğinin Kullanılması: Büyük Ölçekli Bir Traktör İşletmesinde Uygulama. Sakarya Üniversitesi Fen Bilimleri Enstitüsü Dergisi, 21(2), 242-251. 
12. Adalı, M.R., Erdem, H., 2017. Isıtma Soğutma Sistemleri Üreten Bir Fabrikada Yalın Üretim Araçları Kullanılarak Montaj Hattı Dengelenmesi. Endüstri Mühendisliği Dergisi, 28(2), 19-32.

13. Marodin, G.A., Frank, A.G., Tortorella, G.L., Fetterman, D.C., 2017. Lean Production and Operational Performance in the Brazilian Automotive Supply Chain. Total Quality Management \& Business Excellence, 30(3-4), 370-385.

14. Kim, C.S., Spahlinger, D.A., Kin, J.M., Billi, J.E., 2006. Lean Health Care: What Can Hospitals Learn from a World-class Automaker? J. Hospital Med.; 1(3), 191-199.

15. Yalın Enstitü Derneği, Yalın Kavramlar Sözlüğü, 2016. Optimist Yayınevi, s.156.

16. Erozan, İ., 2017. Geleneksel ve Modern Üretim Sistemleri. Monopol Kitapevi, s.432.

17. Orkun, Ü., 2008. Dünya Klasında Üretim Uygulamalar1-Fiat'ta Yalın Dönüşüm, Altı Sigma- Yalın Konferansları, TMMOB, İzmir, 09-11 Mayıs 2008.

18. URL1: www.lean.org.tr.

19. Pekin, E., Çil, İ., 2015. Kauçuk Sektörü PokaYoke Uygulaması. SAÜFen Bilimleri Dergisi, 2, 163-170.

20. URL2: www.leanacademy.com.tr.

21. URL3:www.yunus.hacettepe.edu.tr/ yurdugul /3/indir/Guvenirlik.pdf

22. Kalaycı, Ş., 2008. SPSS Uygulamalı Çok Değişkenli İstatistik Teknikleri. Asil Yayın Dağıtım Ltd. Şti, s.425. 